\title{
Mundo-Vida Travesti: Abordagem Fenomenológica das Travestilidades
}

\author{
Edmar Henrique Dairell Davi ${ }^{1}$ \\ Centro de Ciências da Saúde,Universidade Federal do Recôncavo da Bahia, \\ Santo Antônio de Jesus, BA, Brasil \\ Maria Alves de Toledo Bruns \\ Programa de Pós-Graduação em Psicologia da FFCL/USP, Ribeirão Preto, SP, Brasil \\ e Programa de Pós-Graduação em Educação Sexual/UNESP, Araraquara, SP, Brasil
}

\section{Resumo}

O objetivo deste texto é compreender os significados e os sentidos que três travestis atribuem às suas vivências enquanto profissionais do sexo. Parte-se da premissa de que as travestis, ao serem excluídas de suas famílias e do mercado formal de trabalho, tenham na prostituição um caminho "natural", um "destino" ou refúgio devido ao preconceito contra estas pessoas que rompem com padrões de gênero. No entanto, indagando-se este fenômeno, observa-se que além de garantir a sustentabilidade econômica das travestis, o mercado do sexo influencia a construção da travestilidade de diferentes maneiras. Nesta perspectiva, conduzimos esta análise com o suporte do método fenomenológico e das ideias do filósofo Maurice Merleau-Ponty para compreendermos a vivência de três travestis entre 24 e 42 anos de idade pertencentes à classe D. A análise compreensiva apontou três categorias: "O mundo da pista", que compreende o espaço onde acontece a construção do ser-travesti; "Deslocamentos", que trata do processo de resignificação do ser-travesti quando elas se movimentam e ocupam espaços para além da prática prostitucional; e "Perspectivas", categoria na qual as travestis apontam seus sonhos e projetos existenciais. Estas categorias nos ajudam a compreender a vivência na prostituição como uma experiência que possibilita a subsistência e que também proporciona a elaboração de modo de ser específico expresso a partir da linguagem, da corporalidade e de outros elementos que compõem o "mundo-vida travesti".

Palavras-chave: Travestis, prostituição, fenomenologia, Merleau-Ponty.

\section{Transvestite Life-World: A Phenomenological Approach to Transvestility}

\begin{abstract}
The objective of the present article is the understanding of the meanings and senses that three transvestites attribute to their experiences as sex professionals. We derive from the premise that transvestites, being excluded from their families and from the formal job market, find in the prostitution activity a "natural' course, their "fate", or refuge given the prejudice against such individuals who break way from gender patterns. However, the questioning of such phenomenon led us to observing that besides guaranteeing the transvestites' a living, the sex market influences the construction of transvestility in various ways. From that perspective, we carry out our analysis supported by the phenomenological method and
\end{abstract}

Endereço para correspondência: Avenida Carlos Amaral, 1015, Cajueiro Santo Antônio de Jesus, BA, Brasil, CEP 44570-510. Tel.: (75) 3632-6830.E-mail: edmardavi@ufrb.edu.br e toledobruns@uol.com.br/ sexualidadevida.com.br

Esta pesquisa recebeu apoio financeiro da Coordenação de Aperfeiçoamento de Pessoal de Nível Superior (Capes) por meio de bolsa de doutorado. 
ideas of philosopher Maurice Merleau-Ponty in order to understand the life experience of these three Class D transvestites aged between 24 and 42. Our comprehensive analysis pointed out three categories: "The street", where the construction of the being-transvestite takes place; "Displacement", which deals with process of resignifying the being-transvestite when they move and occupy spaces that are beyond their prostitution practice; and "Perspectives", category in which the transvestites reveal their dreams and life projects. These categories help us to understand the life experience in prostitution as an experience that enables not only their subsistence but also the elaboration of the specificities expressed through the language, corporality, and other elements that comprise the "transvestite life-world".

Keywords: Transvestites, prostitution, phenomenology, Merleau-Ponty.

\section{Mundo-Vida Travesti: Abordaje Fenomenológico de los Travestismos}

\section{Resumen}

El objetivo de este texto es comprender los significados y los sentidos que tres travestis atribuyen a sus experiencias como profesionales del sexo. El texto se basa en la idea de que las travestis, al ser excluidas de sus familias y del mercado laboral formal, ven la prostitución como un camino "natural", un "destino" o asilo debido a la discriminación hacia las personas que no siguen los patrones de género. Sin embargo, al analizar este fenómeno, podemos observar que, además de garantizar el sustento económico de las travestis, el mercado del sexo influye en la construcción del travestismo de distintas maneras. Desde esta perspectiva, realizamos este análisis con base en el método fenomenológico y en las ideas del filósofo Maurice Merleau-Ponty, para comprender la experiencia de tres travestis con edades entre 24 y 42 años, que pertenecen a la clase D. El análisis comprensivo señaló tres categorías: "el barrio chino", que incluye el lugar donde ocurre la construcción del ser-travesti; "desplazamientos", que trata del proceso de resignificación del ser-travesti cuando se desplazan y ocupan espacios más allá de la práctica de la prostitución; y "perspectivas", categoría en la cual las travestis señalan sus sueños y proyectos existenciales. Estas categorías nos ayudan a comprender la experiencia de la prostitución como algo que hace posible la subsistencia y que proporciona la creación de una forma de ser específica, que se expresa con el lenguaje, la corporalidad y otros elementos que forman el "mundo vida travesti".

Palabras clave: Travestis, prostitución, fenomenología, Merleau-Ponty.

Este trabalho investiga a história de vida três travestis com a perspectiva de compreendermos os significados e os sentidos por elas atribuídos às suas trajetórias de vida dentro do universo da prostituição. A existência desta prática se expressa como um fenômeno atemporal que ultrapassa os limites de gênero e geográficos, a repressão, o estigma, a discriminação, dentre outras barreiras. Na atualidade, o corpo se tornou um objeto de consumo - aberto a transformações e correções cada vez mais profundas, e a prostituição ganha visibilidade nas ruas das grandes cidades onde homens, mulheres e travestis se colocam à "venda" no mercado sexual e em outros cenários do consumo erótico (Moraes, 2011).
Muitos profissionais do sexo buscam não só o sustento financeiro, mas, conforme Guimarães e Bruns (2010), procuram ascender socialmente através do acesso a determinados bens de consumo e, em outros casos, constroem sua identidade de gênero através da vivência no mercado do sexo, obtendo também algum tipo de prazer nestas experiências. Desta perspectiva, observa-se, então, que a prática da prostituição assume diferentes significados para aqueles e aquelas que vivem nesse universo.

Pesquisadores como Benedetti (2005), Duque (2011), Kulick (2008), Pelúcio (2009), Silva (2007), entre outros, já indicaram que a prostituição vem sendo o principal destino, muitas vezes tido como único, para a sociabilidade da 
experiência das travestis. Ainda que muitas delas não tenham vínculo e/ou exerçam atividades no mercado do sexo, diferentes estudos demonstram que continua forte a presença da prostituição na construção do ser-travesti.

No Brasil, a construção da vivência travesti se deu tanto nos bailes de carnaval das décadas de 1960 e 1970 quanto na ligação com o universo da prostituição. Para Kulick (2008), no entanto, é esta última característica que marca a imagem do sujeito travesti na atualidade. E ainda conforme o autor, é preciso destacar que nem todas as travestis atuam no mercado do sexo e em momento algum se pode afirmar que a prostituição seja algo indissociável desta vivência.

Para Peres (2012), na atualidade, o mundo-vida travesti está baseado em diversas práticas e experiências que assumem diferentes significados e status simbólico. Neste sentido, o autor se propõe a utilizar o termo travestilidade, contrapondo-o ao termo travestismo, este último ligado a conceitos médicos-psiquiátricos que embasaram as classificações diagnósticas dos transtornos mentais até meados do século XX.

A travestilidade compreende, então, a utilização de um complexo sistema de técnicas para a aquisição de um novo corpo e, consequentemente, de uma nova identidade. Sua mobilidade em diferentes esferas do gênero e da sexualidade permite às travestis transitarem por uma multiplicidade de discursos sobre as posições de sujeito disponíveis na sociedade. Para Peres (2012), a travestilidade contempla "a imensa complexidade das formas de expressão travesti existentes, considerando a heterogeneidade dos modos de ser no mundo que é configurado pela subcultura travesti" (Peres, 2012, p. 267).

Devido ao preconceito e à discriminação presentes no ambiente familiar e escolar, ainda é legítimo pensar a travestilidade recortada pela vivência da prostituição, tanto mais quando se observa que o universo das ruas é fundamental na construção do sujeito travesti (Pelúcio, 2009). É na rua que acontecem, por exemplo, os processos de amadrinhamento das jovens travestis pelas veteranas de pista e a hormonização e aplicação de silicone para feminilizar o corpo ao gosto dos prováveis clientes.
Davi e Bruns (2012), em investigação acerca da vivência de professoras travestis e suas trajetórias no magistério, também observaram que mesmo aquelas que não têm a prostituição como "destino" acabam por perpassar esse caminho como um marco em suas vidas, mesmo que seja para rejeitá-lo posteriormente. A escolha e a possibilidade de atuarem em outras atividades para além do mercado do sexo também foram apontadas pelos autores desta pesquisa que trouxe diferentes histórias de travestis atuantes no magistério, na vida pública e outros empregos formais.

A travestilidade encontra-se ainda nas avenidas, esquinas e praças; o lócus privilegiado de sua elaboração. Dessa forma, é nos territórios da prostituição que as travestis ganham dinheiro, encontram e fazem amizades, paqueram, compram roupas, aprendem técnicas corporais importantes e introjetam as regras desse universo. $\mathrm{Na}$ análise de Benedetti (2005), é na convivência nos territórios de prostituição que as travestis incorporam os valores e formas do feminino, tomam conhecimento dos truques e técnicas do cotidiano da prostituição, conformam gostos e preferências (especialmente os sexuais) e, muitas vezes, ganham ou adotam um nome feminino. Este é um dos importantes espaços que as travestis constroem-se corporal, subjetiva e socialmente.

Diferentes elementos compõem este universo e são aqueles com os quais uma travesti terá de aprender a conviver no processo de construção de sua travestilidade e corporalidade. Além do uso de hormônios, silicone, roupas, linguagem, dentre outros, acrescentam-se o frio, a fome, o sono e a postura - fatores que compõem a vivência travesti no jogo da sedução no mercado do sexo (Pelúcio, 2009). Nesta perspectiva, apreende-se que o corpo travesti é uma construção simbólica, não uma realidade em si. O corpo que desfila nas ruas e avenidas se confunde com o mundo, um mundo-vida específico. Parafraseando o antropólogo Le Breton (2011), podemos dizer que a corporalidade travesti não é fronteira ou átomo isolado, mas é algo indiscernível dentro um todo simbólico. E assim "não existe aspereza entre a carne do homem e a carne do mundo" (Le Breton, 2011, p. 25). 
Para Marilena Chauí (2002), o mundo humano é simbólico e as ações humanas têm o poder de transcender uma dada situação por outra que lhe confere nova significação. Ainda, na visão de Chauí (2002), há a preocupação em entender os sentidos e os significados que as pessoas atribuem às coisas, uma vez que os sujeitos não se dirigem direta e simplesmente às coisas em sua mera presentidade, mas sim mediados pela trama de significados em que as coisas vão se enredando ao aparecer.

Nesta perspectiva, refletiremos sobre a vivência travesti que subverte os padrões de gênero e alcança visibilidade na sociedade hodierna. As travestis modificam seus corpos por meio de cirurgias plásticas, aplicações de silicone, ingestão de hormônios, dentre outras práticas. Essa trajetória se expressa não apenas pelas intervenções estéticas que vêm sendo altamente valorizadas pelo paradigma da visibilidade, mas também pelo mercado de consumo apreciado pelas travestis de modo a atenderem as exigências de seus clientes.

As travestis ressignificam e transformam seus corpos através de intervenções profundas, e muitas vezes permanentes, para serem exibidos no mercado do sexo. Nesse processo dialético de intervenções provisórias no corpo as travestis esboçam e recriam seus contornos de modo a lhe propiciar novos sentidos a sua prática prostitucional trans.

Como expressa, Merleau-Ponty (2006),

Quer se trate do corpo do outro ou de meu próprio corpo, não tenho outro meio de conhecer o corpo humano senão vivê-lo, quer dizer, retomar por minha conta o drama que o transpassa e confundir-me com ele. Portanto, sou meu corpo, exatamente na medida em que tenho um saber adquirido e, reciprocamente, meu corpo é como um sujeito natural, como um esboço provisório de meu ser total. (Merleau-Ponty, 2006, p. 269)

O corpo travesti não é coisa, nem ideia, é movimento, gesto, linguagem, sensibilidade, desejo, dor, historicidade e expressão criadora. Brinca com a reversibilidade corporal na medida em se faz sujeito e objeto. Corpo que longe de ser incompreensível, como somos levados a crer, é perfeitamente esboço provisório para sua fluida ordem simbólica. "O corpo não é, portanto um objeto. A sua unidade é sempre implícita e confusa. Ele é sempre outra coisa que não ele próprio. É no corpo e pelo corpo que tudo vive" (Merleau-Ponty, 2006, p. 208). Isto significa que é nessa dialética que o mundo-vida travesti acontece de modo transitório e inesgotável.

Dessa perspectiva merleaupontyana, nosso objetivo é compreender os significados e sentidos que três travestis atribuem às suas vivências prostituicionais. Fenômeno complexo e instigante que ganha visibilidade nos dias atuais na e pela reatualização do mundo-vida travesti. Investigamos assim, as vivências dessas três colaboradoras que se dispuseram a relatar suas histórias de vida que foram compreendidas a partir trajetória da pesquisa qualitativa fenomenológica.

\section{Método}

$\mathrm{Na}$ presente pesquisa, optamos por adotar o pensamento fenomenológico como guia na aproximação à experiência vivida das travestis e o seu caminhar no universo da prostituição. A opção pela fenomenologia se deve à assunção de uma atitude com valor de método que pode proporcionar uma visão íntima e ampla da realidade humana com grande abrangência para acolher o vivido (Holanda, 2009). A fenomenologia é um método e como tal nos permite o acesso livre ao mundo, aos fenômenos e à própria constituição do sujeito que acessa e interage com o mundo.

A opção por um método pressupõe uma questão a ser resolvida e envolve determinada concepção ou suposição de realidade, ainda que provisória. Não é possível se falar de método desvinculado do fenômeno de estudo (Furlan, 2008). Nesse sentido, nossa escolha traduz uma posição em termos epistemológicos e um método de inspiração fenomenológica parece o mais adequado quando se pretende investigar e conhecer a experiência do outro, uma vez que o ato do sujeito de contar a sua experiência não se restringe a dar a conhecer os fatos e acontecimentos da sua vida, mas significa, além de tudo, uma forma de existir com-o-outro; significa com-partilhar o seu ser-com-o-outro (Dutra, 2002). 
Por ser a fenomenologia um discurso esclarecedor, optamos pela técnica da história de vida focal, guiada por uma questão única, numa linguagem comum à compreensão do fenômeno, como estratégia de pesquisa para desvelarmos a vivência de três travestis e compreender suas trajetórias no mercado do sexo.

É importante ressaltar que a história de vida focal é uma modalidade da história oral em que o informante tem maior liberdade para dissertar livremente sobre suas experiências vividas, o que vai ao encontro do objetivo de nossa pesquisa. Para Moreira (2004), o método da história de vida focal investiga a visão da pessoa acerca das suas experiências subjetivas de certas situações inseridas em algum período de tempo de interesse ou se refere a algum evento ou série de eventos que possa ter tido algum significado para o respondente. O colaborador faz uma descrição de sua vida ou de alguma parte dela.

\section{Procedimentos}

Entramos em contato com as colaboradoras, para quem foi entregue uma carta apresentando o objetivo da pesquisa e solicitando o agendamento da entrevista. Esta foi precedida da assinatura do Termo de Consentimento Livre e Esclarecido, que autoriza sua gravação. Também foi aplicado um questionário socioeconômico para traçar o perfil das participantes. As entrevistas tiveram a duração média de 80 minutos. Para um maior aprofundamento da experiência pessoal das entrevistadas em relação ao fenômeno estudado, iniciamos com a questão orientadora: Fale da sua vivência afetivo-sexual em relação à sua trajetória como profissional do sexo. Os encontros foram realizados na sede de uma organização não governamental (ONG) de apoio à população LGBT (lésbicas, gays, bissexuais, travestis, transexuais e trangêneros), localizada numa cidade do interior do Estado de Minas Gerais.

\section{Participantes}

As colaboradoras desta pesquisa foram três travestis frequentadoras das reuniões da citada ONG de apoio à população LGBT. Os critérios para a inclusão das participantes na investiga- ção foram: ser travesti que atue ou tenha atuado como profissional do sexo e aceitar participar da pesquisa. A seguir, apresentamos o perfil socioeconômico das colaboradoras. Antes, no entanto, é preciso esclarecer que optamos pelo uso de pseudônimos a fim de preservá-las. Esclarecemos, ainda, que o motivo pelo qual nos dirigimos a elas no feminino se deve ao fato de se sentirem e se definirem a partir deste gênero.

A primeira colaboradora entrevistada foi Mônica, uma travesti de baixa estatura, de 23 anos e que vive com os pais. De religião católica, pertence à classe $\mathrm{C}$, tem o Ensino Médio completo e trabalha como profissional do sexo e auxiliar de cozinha. A segunda foi Rosana, uma travesti "veterana" de 42 anos que tem Ensino Fundamental incompleto, frequenta a religião espírita e pertence à classe $\mathrm{D}$. Atualmente, ela trabalha como auxiliar de serviços gerais, mas já trabalhou como profissional do sexo e ajudante de bombadeira. Por fim, a terceira colaboradora foi Samantha, uma travesti jovem de 24 anos, com Ensino Médio completo, sem religião e pertencente à classe D. Ela vive em uma república com outras meninas com as quais compartilha, além do espaço físico da pensão, as lições e os problemas da vida de profissional do sexo.

\section{Momentos de Análise}

As descrições das colaboradoras foram submetidas ao processo da análise fenomenológica que, segundo Bruns (2007), ocorre em quatro momentos. O primeiro momento caracteriza-se pela transcrição das entrevistas e leitura ampla de todas as descrições, do início ao fim, com o objetivo de apreender o sentido geral do fenômeno estudado. $\mathrm{O}$ segundo momento é marcado pela intenção de caminhar para a elaboração da discriminação das unidades de significado, as quais são extraídas após a releitura de cada depoimento, tendo em vista que não existem por si mesmas, mas somente em relação à interrogação que o pesquisador dirige ao fenômeno. O terceiro momento diferencia-se pelo seguinte aspecto: após a obtenção das unidades de significado, o pesquisador busca agrupá-las em temas ou categorias que expressam o insight psicológico nelas contido; ou seja, é a transformação da linguagem 
coloquial da entrevistada no discurso psicológico. Nesta etapa, cabe ao pesquisador escolher a abordagem teórica que utilizará para analisar o fenômeno. O quarto e último momento baseia-se na integração dos insights contidos em todas as unidades de significado, as quais podem ser agrupadas em temas ou categorias em função das convergências e/ou divergências dos significados atribuídos pelas informantes e que constituem os aspectos essenciais da estrutura compreensiva geral do fenômeno em questão.

\section{Resultados}

\section{Categorias de Análise}

De posse das unidades de significados, passamos à análise compreensiva que nos possibilitou o encontro das seguintes convergências das descrições que assim se apresentam a seguir.

Categoria 1. O mundo da pista: nesta categoria, nossas colaboradoras pontuaram questões que perpassam o universo da prostituição como a violência, o risco de contaminação por doenças e o contato com as drogas, mas também apontaram outros elementos como o aprendizado com as demais travestis, a sensação de pertencimento, os namoros e paqueras etc.

Categoria 2. Deslocamentos: as travestis relataram suas vivências em outros locais de trabalho ou a perspectiva de conseguir outras formas de subsistência; consequentemente, suas falas contemplaram também transformações e resignificações em seus projetos de vida.

Categoria 3. Perspectivas: as colaboradoras ponderaram sobre seus sonhos e projetos e descreveram suas expectativas sobre o alcance de determinados objetivos.

A partir do estabelecimento das categorias, segue-se a interlocução destas com as reflexões teóricas das quais nos aproximamos na compreensão do fenômeno, particularmente, da perspectiva do filósofo Merleau-Ponty.

\section{Análise Compreensiva do Mundo-Vida das Travestis}

As entrevistas foram analisadas conjuntamente e demonstramos as convergências e divergências dos depoimentos que formam as categorias de análise. Desse modo, passemos à discussão da primeira categoria: o mundo da pista. Então, com esses dezesseis anos eu fui pro posto me prostituir. Nesse dia ocorreu um fato de um bandido ir assaltar o posto e matou a minha amiga. Essa minha amiga que morreu no posto foi muito importante pra mim. Me ensinou muita coisa. No dia que ela foi assassinada, eu também fui parar na delegacia pra testemunhar e lá fui maltratada a beça pelos policial da delegacia. Perguntava se eu não tinha vergonha, se não tinha pena da minha família por ficar se prostituindo na rua feito puta. Como eu consegui escapa fiquei com medo da pista, de fazer pista. (Mônica)

Além da bombação, eu tenho muitas histórias de pista [prostituição], de rua, né. Fiz pista uns vinte... vinte e poucos anos no posto P. Mas assim eu gosto de falar de um marido que eu tive por quinze anos. Nós largamos porque assim entrou outro no meio de nós. Ai esse meu marido de quinze anos eu lembro que ele não gostava de eu fazer rua. Eu queria sair e ele não deixava. Eu falava que eu me montava pra ele, ele ficava alegre. Mas ai quando ele saía, eu ia pra pista, ganhar dinheiro [risos]. (Rosana)

Então, o caminho que eu tenho infelizmente é a prostituição, mas uma das coisas que eu tenho feito sempre é buscar, buscar novos caminhos, novas formas de sustentabilidade. Porque com a prostituição a gente sabe que fica muito exposta às DST [doenças sexualmente transmissíveis], a AIDS, ao álcool, às drogas. Então eu acho que se a gente tivesse um trabalho de dia a gente teria que ir até a droga e a gente na prostituição a droga vem até a gente. Então a gente fica muito exposta e muito vulnerável. (Samantha) $\mathrm{O}$ medo que permeia a atividade profissional das travestis que se prostituem, é muitas vezes um sentimento imobilizador. $\mathrm{O}$ perigo as espera nas ruas e esquinas das cidades: inúmeros são os casos de pedras, garrafas com urina e outros objetos arremessados contra elas, inclusive ácido. Outras vezes, o perigo se faz presente 
na cantada de algum cliente ou no deboche de policiais, assim como salientou Mônica sobre as agressões sofridas por ela.

As marcas no corpo acabam se tornando signos que remetem a um episódio doloroso e triste e que a afetou Mônica profundamente: " $\mathrm{eu}$ fui ficando grilada com a violência". Para Merleau-Ponty (2006) nosso corpo, coisa sensível entre as coisas, é sensível para si, está sempre reflexionando: objeto e observador. É pelo corpo que o mundo é dado a ser vivido por mim, pois "o corpo é o veículo do ser no mundo; ter um corpo é, para um ser vivo, juntar-se a um meio definido, se confundir com certos projetos e se engajar neles continuamente" (Merleau-Ponty, 2006, p. 97). As marcas no corpo de Mônica fazem com que a violência do passado seja presentificada por ela nos diferentes momentos de sua trajetória.

$\mathrm{Na}$ "batalha", a vida das travestis não é fácil e não há garantias de sobrevivência quando se entra em um carro: o cliente é sempre um indivíduo estranho e desconhecido. Outras vezes, o programa acontece no mato, em algum imóvel abandonado ou ali mesmo, no automóvel, o que aumenta a vulnerabilidade de quem sobrevive de programas sexuais. Por viver em um constante e intenso processo de marginalização, os fatores restritivos à atividade prostitucional da travesti talvez expliquem porque sua identidade sexual se tornou uma categoria profissional negada e estigmatizada. A partir de sua observação da dinâmica social vivenciada pelas travestis da Lapa, no Rio de Janeiro, Silva (2007) comenta a violência sofrida por esse grupo social: "Pode-se entender o quanto isso deve irritar quem se expõe, com tanto arrojo, a enfrentar todos os preconceitos e a passar todas as humilhações em nome da fidelidade a si mesmo" (Silva, 2007, p. 99).

No entanto, a violência, ainda que assuste e seja reprovada no universo trans, não causa tanto espanto. Algumas situações violentas são, inclusive, entendidas pelas próprias travestis como a única solução para um impasse (Benedetti, 2005), principalmente, quando existem disputas de pontos e de clientes ou mesmo quando uma travesti rouba outras colegas ou cafetinas.
As travestis também reproduzem os papéis sociais de gênero quando se encontram em situações conjugais. Muitas falam da perspectiva romântica de encontrar alguém que as assuma diante da sociedade sem esconder a relação. Nesse sentido, ao "se montar" para o marido, Rosana faz o papel da esposa que se embeleza para o cônjuge e se torna objeto de posse dele. Mas ao sair escondida, Rosana demonstra que as travestis buscam sua autonomia e precisam viver na pista ou dela compartilhar para buscar um sentimento de pertencimento.

O espaço ocupado pelas travestis nas ruas e calçadas se torna um espaço tímico, subjetivado. $\mathrm{Na}$ perspectiva merleau-pontyana, o sujeito não está em seu mundo circundante como um objeto dentro de uma caixa ou um animal em uma jaula, mas habita este mundo que para ele se abra com diversas possibilidades. Uma consequência disso é a constatação de que o espaço ao nosso redor não é simplesmente um espaço físico, mas um espaço investido por nosso corpo: mesmo uma criança que não tenha ainda consciência de seu corpo se move em direção às coisas (Merleau-Ponty, 2006).

Para Benedetti (2005), a rua pode ser o único lugar onde a travesti se sinta bonita e desejada, além de ser um ambiente para se encontrar homens que não se identificam com o universo gay, os chamados "homens de verdade". É na esquina que as travestis têm pela primeira vez a sensação de pertencer a algum lugar. A rua pode se apresentar como um ambiente de acolhimento quando meninos efeminados são colocados para fora dos espaços domésticos. Mas não é simples ficar na rua. Há toda uma demarcação de territórios dentro do mercado do sexo: divisão se relaciona com o capital corporal de quem divide os espaços e marca identidades que são classificadas por categorias e hierarquias baseadas no poder econômico e na violência.

Rosana relata que outra pessoa entrou na relação e isso a fez trocar de marido. Isso ocorre porque há certa concorrência entre os homens para serem amantes das travestis e delas receberem presentes, dinheiro e conforto. As travestis recebem em contrapartida a confirmação de sua feminilidade e de sua capacidade de sedução. 
Samantha, por sua vez, nos fala do contato com as drogas e da exposição a diferentes riscos presentes na noite. Para as travestis, o uso de álcool e até de outras drogas ilícitas se torna o meio para suportar uma rotina tão desafiante. O tornar-se travesti é também um processo que se dá pela resistência aos perigos. Ao serem rejeitadas em casa e no mercado de trabalho, muitas travestis buscam nas drogas a fuga ou a força necessária para lidar com as adversidades do mundo da prostituição. A dependência química é um problema crônico entre essa população, mas, infelizmente, o acesso aos serviços de orientação e tratamento também esbarram no preconceito. Muitas travestis se sentem humilhadas pelos prestadores de serviços e estes geralmente não tem capacitação para atendê-las de maneira digna (Garcia, 2008).

Ao buscar saídas por um serviço de saúde que seja adequado às necessidades das travestis, nossas colaboradoras expõem outras possibilidades de vivência da travestilidade que são discutidas na categoria Deslocamentos:

Eu já me prostitui mas esse ano eu tô trabalhando num restaurante como auxiliar de serviços gerais. As pessoas me respeitam, me tratam bem. Elas me vê como uma pessoa normal. Porque lá no meu trabalho eu não vejo o preconceito. Eu tenho peito, cabelo grande e bunda arredondada, no serviço ninguém me incomoda por causa disso. Eu me vejo como todas as pessoas normais, eu não vejo diferença nenhuma em mim. (Mônica)

Hoje eu acho melhor trabalhar porque fazer pista é muito humilhante pra gente. Por causa de mixaria a pessoa humilha, faz palhaçada com a gente. Muitos até agride porque depois parece que fica com vergonha que pegou travesti. Eu também tenho Aids. Eu usei bastante camisinha, mas eu peguei o HIV acho que de um vício meu. Há doze anos que eu tenho esse vírus. Já usei muita droga que acaba com a gente. $O$ corpo não aguenta mais. (Rosana)

Uma das coisas que a gente tem vontade é que o SUS [Sistema Único de Saúde] garantisse pra nós um médico que pudesse fazer essa cirurgia pra gente. E o SUS liberasse um médico que colocasse as prótese pra gente, porque é muito caro e muitas das vezes elas se submetem ao processo do silicone industrial por ser mais acessivel. Várias amigas nossas que já morreram devido à gravidade do silicone industrial no peito pelas infecções. (Samantha)

A descrição de Samantha pode parecer estranha a uma pessoa desavisada, pois, para muitos, as travestis são uma categoria de pessoas abjetas, marginais e perigosas. Elas são relegadas ao campo desvalorizado do feminino, pois se trata de seres do sexo masculino que abdicaram do "privilégio da masculinidade", e têm sua identidade associada a um desvio de caráter que excede o vergonhoso e se aproxima do estigmatizável (Duque, 2011). Como estariam então reivindicando o direito de colocar próteses de silicone financiadas pelo SUS?

A possibilidade de reivindicar e de brigar por direitos se insere, de um modo geral, dentro das expectativas do movimento LGBT, que existe no Brasil desde a década de 1970. As travestis, como um segmento desse movimento, têm exigências específicas e até mesmo contrárias às de outras partes da população LGBT. Aqui cabe ressaltar as características do processo no qual as travestis passam a se enxergar como detentoras de direitos e proprietárias de discurso técnico embasado na perspectiva dos direitos sexuais (Vianna, 2012). Samantha faz parte de uma ONG e dessa forma participa de reuniões/ congressos pelo Brasil para discutir a pauta de reivindicações e direitos das travestis. Essa mobilização em torno da sexualidade como parte dos direitos humanos promove, conforme Vianna (2012), "sutis deslocamentos às vezes dentro do mesmo conjunto de sujeitos já consagrados, mudando a forma de falar das relações de poder em que tais sujeitos estariam colocados e dando à sexualidade uma posição de destaque para seu fazer-se político" (Vianna, 2012, p. 231).

Atualmente, várias ONGs se associaram ao Estado na perspectiva de conseguirem recursos através de projetos e políticas públicas para lidar com os problemas enfrentados pelas travestis. Esse processo foi observado por Reis (2008), ao 
investigar a constituição de demandas do movimento das transexuais e das travestis:

as políticas públicas constroem subjetividades que se mostram ou se colocam através de duas dobradiças: por um lado, corporalidades específicas e, por outro, valores, emoções, autopercepção e modos de vida de um grupo que articula demandas pela visibilidade de sua condição desvinculada de ideias patologizantes. (Reis, 2008, p. 127)

Importante é destacar, então, o deslocamento de significado que o corpo travesti assume: da abjeção, da marginalidade à posição de exigência, ou pelo menos à possibilidade de reivindicar recursos, espaço e visibilidade. Ainda que observemos a permanência do estigma que acompanha as pessoas com HIV, como citado por Rosana, e suas diversas consequências negativas.

Da descrição de Mônica, podemos apreender que à medida que ela passa a frequentar um novo ambiente vão se transformando as relações que ela mantém com os outros e consigo mesma. $\mathrm{Na}$ perspectiva de Merleau-Ponty (2006), é próprio do ser humano não poder ser totalmente engolfado ou consumado por esse mundo em que vive, nem por coisa alguma que ele pense, sinta ou produza. As ideias mudam, assim como mudam as sensações, as emoções, as perspectivas, os interesses, as lembranças. Pois temos um corpo aberto às ações, "e é possível retomar aquilo que está sedimentado, e projetar as situações possíveis em resposta a um mundo que o corpo compreende. É possível escrever uma nova história, e é este o modo original da consciência enquanto "eu posso"' (Merleau-Ponty, 2006, p. 437).

Dessa forma, Mônica vai construindo um novo significado para sua existência e para sua corporalidade: "eu não vejo diferença nenhuma em mim". Além disso, Mônica nos fala de seu desejo de ser vista como uma pessoal normal, de ser reconhecida em sua humanidade. Para ela, esta perspectiva se consolida na medida em que passa a trabalhar em um restaurante e a ser aceita por outras pessoas. Seu corpo feminino ganha inteligibilidade em um ambiente determinado às mulheres ou muitas vezes aos "seres subalternos". A conquista desse espaço é muito importante e não pode ser negada. No entanto, há que se perguntar: será que ela seria aceita em um lugar caracteristicamente masculino?

Sexo e gênero determinam territórios de pertencimento e aqueles que burlam essas determinações sofrem suas penalidades. As travestis, ao assumirem a sua condição, se tornam seres abjetos. E os abjetos, de acordo com Pelúcio (2009), poluem, contagiam, devem ser evitados; o que é considerado sujo ou suscetível de poluição não é outra coisa senão a perturbadora "matéria fora do lugar". Assim, muitos comportamentos foram instituídos como "fora do lugar", na ilegitimidade, como sexualidades periféricas.

A normalidade se circunscreve a partir da fixação desses territórios onde vivem os corpos que não importam, uma vez que o abjeto é também o não humano. A abjeção tão pouco é um mero estado de coisas e posições de sujeitos; ela basicamente suscita emoções relacionadas às valorações que dependem dos contextos particulares de produção de sentidos do antagonismo.

Ao conquistar espaço no restaurante, Mônica obtém a satisfação de ser percebida como pessoa normal, de receber das outras pessoas não mais injúrias e calúnias. Sua humanidade, pode se dizer assim, foi restabelecida. Ela consegue que sua alteridade seja reconhecida e não mais usada contra ela, transformando a diferença em desigualdade. Rosana, por sua vez, fala da convivência entre as travestis veteranas e as mais novas. Para ela, o trabalho como auxiliar de serviços gerais é melhor do que aquele como profissional do sexo no qual os valores e os bens são fluídos. Rosana busca retomar sua dignidade por meio de uma atividade na qual não seja tão humilhada. No entanto, o status de soropositiva acaba transformando sua percepção sobre si mesma e sobre seu corpo.

A descoberta da soropositividade tem para a travesti o aspecto de culpa porque ela não se cuidou direito ou se descuidou quando não deveria. "Fazer vício" ou ser "viciosa" remete muitas vezes ao comportamento daquelas travestis que confundem relações sexuais ou profissionais com afetivas. A sensação de castigo pode ser observada em muitos relatos de travestis contaminadas pelo HIV (Kulick, 2008). 
Pelúcio (2009) observou que as ações preventivas se voltam para a travesti, e não para o cliente, tendo ela de mudar comportamentos (e o próprio corpo) enquanto ele não terá que alterar suas práticas eróticas. Os clientes, em sua maioria, se desresponsabilizam pelas consequências do ato, atitude socialmente vista como tipicamente masculina. E como relatou Rosana: "Muitos até agride porque depois parece que fica com vergonha que pegou travesti".

$\mathrm{Na}$ descrição de Rosana pode-se observar também o que Monteiro (2002) chama de "hierarquização do risco". Esta hierarquia relaciona-se com a classificação do parceiro ou parceira como alguém conhecido/familiar e desconhecido/estranho, e as associações que daí advém: confiança, segurança versus perigo e risco, respectivamente. Ao contrair o vírus de um "vício", recai sobre a travesti a responsabilidade pela sua soropositividade. Muitas acabam sendo chamadas de "bichas burras" quando isso acontece.

Apesar das dificuldades e dos desafios, novas Perspectivas se delineiam para nossas colaboradoras:

Já pensei em mudar o meu corpo, mas desde que eu me prepare. Tenho que tirar a barba, fazer o meи corpo. Me fazer de um jeito que as pessoas me olhem sem me julgar, que me olhem de uma maneira que eu mereça ser vista.Quero assim, ficar belíssima, sabe! (Mônica)

Assim, apesar da doença, os planos é da gente melhorar cada vez mais, né. Tem que trabalhar pra conseguir as coisas. E com o virus, a gente fica mais visada. As pessoas ficam chamando a gente de finada, de quase morta . . preconceito mesmo, né. . . . E assim tem que trabalhar, já que tá com essa doença mesmo. Só penso no dia de amanhã. Ganhar dinheiro, ter minha casinha bem montadinha de novo. Porque já tá montada, mas eu quero ter mais coisas. (Rosana)

Assim, eu nunca trabalhei em outra coisa, mas agora eu sei que tem aquele programa do primeiro emprego. O governo tem esse programa e umas das coisas que a gente tá querendo, que a gente tá correndo atrás, é que faça valer esse programa também pras travestis, pro cidadão travesti, transexual, pra gente que nunca trabalhou. A gente precisa é de oportunidade. Acho que se eu começar a trabalhar, eu queria arrumar um jeito de voltar a estudar pra poder ocupar o tempo. (Samantha)

A perspectiva de ruptura com o mundo da prostituição aparece no relato de Samantha e ganha visibilidade no universo travesti. Esse aspecto também é citado por Carvalho (2011), que aponta o surgimento, dentro deste universo, de novas iniciativas que ampliam as possibilidades de atuação profissional da população trans. Para o autor, a existência de ONGs e projetos que auxiliam na construção de uma nova identidade a partir da atuação política favorece a "purificação" de aspectos estigmatizantes relativos à travestilidade. Ainda conforme Carvalho (2011), cursos de capacitação oferecidos por estas entidades configuram novo espaço mais formal de aprendizagem da carreira militante, o que aumenta a conscientização das travestis sobre seus direitos, reduzindo sua vulnerabilidade.

Apesar da perspectiva de ruptura com o universo da prostituição, o mundo do trabalho para as travestis ainda se apresenta cheio de obstáculos. Rodrigues e Nardi (2009) apontam duas posições ocupadas por jovens homossexuais no mercado de trabalho: a primeira estaria ligada à precariedade da inserção desses jovens no mercado formal, em decorrência da fragilidade dos suportes sociais, restando como alternativa de trabalho para eles o mercado informal, com atividades como entrega de panfletos, bicos e prostituição; a segunda posição é marcada pelo acesso desses jovens ao mercado formal, o qual se constitui a partir de algumas restrições impulsionadas fundamentalmente pela regra heterossexista presente nos contextos de trabalho.

Ainda conforme esses autores, a presença de alguns jovens homossexuais e travestis em programas governamentais que visam a sua inserção no mercado formal representa maiores chances de ingresso em postos mais qualificados do mercado de trabalho, isso na medida em que tais programas não reproduzam a lógica heteronormativa, que acaba por expulsar esses jovens da possível trajetória profissional.

Se existe preconceito contra gays, lésbicas e bissexuais, talvez a situação das travestis seja 
ainda mais delicada, pois assumem uma sexualidade considerada trans que rompe com a "determinação biológica" dos gêneros assumindo, muitas vezes, por 24 horas por dia essa transcondição. Dessa forma, elas serão, por vezes, levadas a assumirem um lugar marginalizado na sociedade, sem garantias e direitos (Carvalho, 2011).

Na história de Samantha, é importante destacar ainda que, ao participar do movimento organizado pelas travestis, sua corporalidade ganha novos significados e seu mundo-vida se transforma. O corpo travesti se torna um sistema de ações possíveis: "um corpo virtual cujo 'lugar' fenomenal é definido por seu objetivo e pela sua situação" (Merleau-Ponty, 2006, p. 289).

Para Mônica, a transformação corporal fará com que ela seja aceita ou menos rejeitada pelas outras pessoas. Mas "ser travesti" é um processo que nunca se consolidada totalmente. E pelo relato de Mônica podemos perceber que o feminino buscado e idealizado passa necessariamente por transformações profundas: "Tenho que tirar a barba, fazer o meu corpo". É necessário que se planeje e se prepare. O contrário disso é visto de maneira polêmica e até mesmo inaceitável para a maioria das travestis. Intervenções apenas epidérmicas e esporádicas podem ser lidas como falhas morais, denunciadas através do descuido com o corpo, o desleixo, a preguiça em se arrumar, a covardia em não aplicar o silicone, entre outras atitudes.

Ainda na descrição de Mônica, observa-se que as travestis reconhecem um corpo masculino que subjaz: o crescimento da barba. Pelúcio (2009) ainda acrescenta o temor da calvície, do câncer de próstata, do alojamento do silicone no saco escrotal, dentre outros problemas.

Para Merleau-Ponty (2006), nosso "equipamento psicofisiológico" deixa aberta várias possibilidades de ser no mundo e as travestis, ao atuarem sobre sua corporalidade, modificando seu gênero, se projetam rumo ao "não acontecido", a outra realidade possível. "Se o sujeito está em situação, se ele não é nada senão uma possibilidade de situações, é que ele só realiza a sua ipseidade sendo efetivamente corpo e entrando por esse corpo no mundo". (Merleau-Ponty, 2006, p.
467). Assim, as travestis têm no corpo, na busca por um ideal de beleza, a base de seus horizontes, o caminho de seus projetos futuros.

A atuação das bombadeiras e o processo doloroso que elas empreendem no corpo das outras travestis ganha legitimidade dentro do grupo. Rosana, como uma travesti veterana, também encontra seu lugar dentro desse processo no qual o gênero feminino e o estigma encontram na dor o seu vínculo. A feminilização precisa ser posta em camadas sobre o corpo, numa reiteração diária sem fim. É esse processo que faz recair sobre elas o estigma, impedindo-as de receberem a aceitação plena da sociedade (Pelúcio, 2009).

Como discutimos acima, para Rosana, contrair o HIV é um constrangimento e uma grande infelicidade. Kulick (2008) nos fala do "estigma do aidético", que torna as travestis visadas entre elas mesmas e entre os clientes. Kulick (2008) observa também que o diagnóstico que as travestis fazem para os outros deve ser entendido como afirmação de seus sentimentos em relação às outras travestis - os desafetos geralmente têm AIDS. Por isso, Rosana reclama das palavras ofensivas como "finada" e "quase morta".

Por outro lado, Rosana tem o desejo de continuar trabalhando e de melhorar sua casa. As casas das travestis, muitas vezes, são cheias de regras e mesmo de perigos devido à rivalidade que podem surgir entre as moradoras e entre estas e a cafetina ou dona da casa. Apesar disso, não significa que o espaço doméstico não seja um lugar de segurança, repouso, satisfação e hospitalidade. Rosana descreve o ambiente de seu lar, traçando claros limites entre este e a rua.

Para as travestis é na casa, esse espaço afetivo e significativo, que elas podem experimentar o conforto de estarem entre iguais e, mesmo, de abandonarem-se a um relaxamento doméstico: andam descuidadas, desarrumadas. Ainda assim, é também na casa que as travestis reiteram e refazem cotidianamente a sua condição. É no ambiente doméstico que cumprem o ritual e o exercício performativo cotidianos de materializarem o feminino em seus corpos.

$\mathrm{Na}$ perspectiva merleau-pontyana, o nosso "espacializar" não se limita ao "estar aqui", pois inclui o "ter estado lá" e o que poder vir a "estar 
acolá", reunidos numa compreensão global da vivência que temos do ambiente. "Ser corpo . . - é estar atado a um certo mundo, e nosso corpo não está primeiramente no espaço: ele é no espaço" (Merleau-Ponty, 2006, p. 205). Dessa forma, no relato de Rosana, sua casa remete ao conforto do presente, mas também aos projetos do futuro e da possibilidade de enfrentar os desafios de sua soropositividade.

\section{Considerações Finais}

O processo de emergência das travestilidades nos faz pensar a condição trans situada entre a coragem de afirmação de um modo de existência frente às determinações do sistema sexo/gênero/ desejo/práticas sexuais, que, como instrumentos de manutenção da heteronormatividade, impõem modelos de verdades universais e cristalizações identitárias demarcadas por códigos baseados na visão biológica do corpo.

$\mathrm{Na}$ constituição e fluidez de seu mundo-vida, as travestis expressam singularidades possíveis em consequência de uma trajetória criadora e transformadora que faz das travestilidades ensaios de enfrentamento dos padrões normativos que insistem em se fixar em seus corpos, sensibilidades e pensamentos. Suas histórias de vida nos ajudam a compreender os significados que atribuem a esse processo de transformação e a suas vivências no mercado sexual. Uma travesti não se faz somente com roupas e adereços femininos, mas também com hormônios para arredondar o corpo, com silicone para dar forma e volume aos seios e quadris. A dor durante o processo aplicação dá sentido e dignifica suas vivências e marca suas histórias. Além disso, o ser travesti também se faz na pista no contato com as cafetinas, madrinhas/mães, que ora acolhem ora maltratam e ensinam os caminhos da noite no mercado do sexo. A rivalidade e as amizades marcam também a vivência travesti, pois, ali está o espelho onde se deve olhar e onde são encontrados os modelos para subir e permanecer "em cima do salto".

A violência e a exclusão ainda são relatadas com frequência pelas travestis. E passam a constituir uma maneira de lidar com os outros e com elas mesmas. Ao verem seus corpos e seus desejos relegados ao segundo plano, acabam por adoecer e trilham caminhos "mais fáceis" para suportar a dor do ostracismo. As drogas, as bebidas, o "truque", dentre outros artifícios são usados pelas travestis como mecanismos para amenizar seu sofrimento.

Além desses caminhos, para as travestis entrevistadas, há a tentativa de romper com o universo da prostituição, abrindo novos espaços para o corpo travesti e novos significados para sua atuação. Trabalhar em restaurantes, em salões de beleza, em ONGs LGBT e em outros lugares, ainda que limitados, representam mudanças para as travestis que buscam recuperar sua cidadania. A busca pelo respeito e o fim da discriminação é um sonho comum relatado pelas travestis que tiveram desde a infância seus desejos cerceados a partir do momento que assumiram sua condição. Essas questões nos levam para outras questões que dizem respeito à emergência de novos sujeitos de direitos que reivindicam outras referências e posicionamentos diante da vida, solicitando revisão das categorias e classificações que colocam as travestilidades associadas a desvio, doença, crime e abjeção.

As histórias por nós analisadas nos fazem refletir sobre as trajetórias daqueles/daquelas que rompem com as normas sociais e os padrões de gênero assumindo um lugar que lhes permita sentir-se bem, satisfazer seus desejos e construir uma estilística da existência que expresse sua singularidade humana, mesmo que isso signifique sofrer violações e violências e até mesmo correr riscos de morte. Nossa perspectiva é de que as investigações e os estudos sobre o universo trans devam priorizar análises que positivem suas vivências e trajetórias existenciais e rompam com as categorizações patologizantes, com os pensamentos binários, de modo a ampliar o debate e resignificar conceitos e metodologias de compreensão das possibilidades do existir humano.

Assim, não defendemos uma posição regulamentadora ou abolicionista em relação à prostituição. Preocupamos-nos em discutir e compreender os diversos sentidos que as travestis constroem sobre esta prática a partir de suas vivências e dentro de contextos específicos. 
Torna-se fundamental que políticas de atenção a esse grupo trabalhem os sentidos da corporalidade, seu empoderamento, e, a partir de então, criem-se estratégias de apoio a essas pessoas como cidadãs, como seres-no-mundo.

\section{Referências}

Benedetti, M. (2005). Toda feita: Corpo e gênero das travestis. Rio de Janeiro, RJ: Garamond.

Bruns, M. A. T. (2007). A redução fenomenológica em Hurssel e a possibilidade de superar os impasses da dicotomia subjetividade - objetividade. In M. A. T. Bruns \& A. Holanda (Eds.), Psicologia e pesquisa fenomenológica: Reflexões e perspectivas (pp. 65-75). São Paulo, SP: Alínea.

Carvalho, M. F. (2011). A (im)possível pureza: Medicalização e militância na experiência de travestis e transexuais. Sexualidad, Salud y Sociedad, 8(1), 36-62.

Chauí, M. (2002). A experiência do pensamento. Ensaios sobre a obra de Merleau-Ponty. São Paulo, SP: Martins Fontes.

Davi, E. H. D., \& Bruns, M. A. T. (2012). Profesoras travestis: trayectorias y experiências. Revista Intercontinental de Psicología y Educación, 14(2), 121-142.

Duque, T. (2011). Montagens e desmontagens. Desejo, estigma e vergonha entre travestis. São Paulo, SP: Annablume.

Dutra, E. (2002). A narrativa como uma técnica de pesquisa fenomenológica. Estudos de Psicologia (Natal), 7(2), 371-378.

Furlan, R. (2008). A questão do método na Psicologia. Psicologia em Estudo, 13(1), 25-33. doi:10.1590/S1413-73722008000100004

Garcia, M. R. V. (2008). Prostituição e atividades ilícitas entre travestis de baixa renda. Cadernos de Psicologia Social do Trabalho, 11, 241-256.

Guimarães, R., \& Bruns, M. A. T. (2010). Garota de programa. Uma nova embalagem para o mesmo produto. Campinas, SP: Átomo.

Holanda, A. (2009). Fenomenologia e Psicologia: Diálogos e interlocuções. Revista da Abordagem Gestáltica, 15(2), 87-92.

Kulick, D. (2008). Travesti: Prostituição, sexo, gênero e cultura no Brasil. Rio de Janeiro, RJ: Editora da Fundação Oswaldo Cruz.
Le Breton, D. (2011). Antropologia do corpo $e$ modernidade. Petrópolis, RJ: Vozes.

Merleau-Ponty, M. (2006). Fenomenologia da percepção (3. ed.). Rio de Janeiro, RJ: Martins Fontes.

Monteiro, S. (2002). Qual prevenção?Aids, sexualidade e gênero em uma favela carioca. Rio de Janeiro, RJ: Editora da Fundação Oswaldo Cruz.

Moraes, A. F. (2011). O corpo prostituído nas práticas discursivas de organizações dos direitos humanos. In M. Goldenberg (Ed.), Corpo, envelhecimento e felicidade (pp. 199-229). Rio de Janeiro, RJ: Civilização Brasileira.

Moreira, D. (2004). O método fenomenológico na pesquisa. São Paulo, SP: Pioneira.

Pelúcio, L. (2009). Abjeção e desejo. Uma etnografia travesti sobre o modelo preventivo de AIDS. São Paulo, SP: Fundação de Amparo à Pesquisa do Estado de São Paulo.

Peres, W. (2012). Travestilidades nômades: A explosão dos binarismos e a emergência queering. Estudos Feministas (Florianópolis), 20(2), 250271. doi:10.1590/S0104-026X2012000200014

Reis, I. (2008). Transexualidades: Interlocução entre o Direito e a Medicina (Dissertação de mestrado em Antropologia, Universidade de Brasília, DF, Brasil).

Rodrigues, M., \& Nardi, H. (2009). Diversidade sexual e trabalho: Reinvenções do dispositivo. Revista Bagoas: Estudos Gays: Gêneros e Sexualidades, 3(2), 136-145.

Silva, H. (2007). Travesti: Entre o espelho e a rua. Rio de Janeiro, RJ: Rocco.

Vianna, A. (2012). Atos, sujeitos e enunciados dissonantes: Algumas notas sobre a construção dos direitos sexuais. In R. Miskolci \& L. Pelúcio (Eds.), Discursos fora da ordem: Sexualidades, saberes e direitos (pp. 227-244). São Paulo, SP: Annablume.
Recebido: $24 / 05 / 2012$

$1^{a}$ revisão: 02/12/2013

$2^{a}$ revisão: 05/05/2014 Aceite final: 24/06/2014 